\title{
Relevance of animal models to human tardive dyskinesia
}

\author{
Pierre J Blanchet ${ }^{1,2,3,4^{*}}$, Marie-Thérèse Parent ${ }^{2}$, Pierre H Rompré ${ }^{\text {and Daniel Lévesque }}{ }^{5}$
}

\begin{abstract}
Tardive dyskinesia remains an elusive and significant clinical entity that can possibly be understood via experimentation with animal models. We conducted a literature review on tardive dyskinesia modeling. Subchronic antipsychotic drug exposure is a standard approach to model tardive dyskinesia in rodents. Vacuous chewing movements constitute the most common pattern of expression of purposeless oral movements and represent an impermanent response, with individual and strain susceptibility differences. Transgenic mice are also used to address the contribution of adaptive and maladaptive signals induced during antipsychotic drug exposure. An emphasis on non-human primate modeling is proposed, and past experimental observations reviewed in various monkey species. Rodent and primate models are complementary, but the non-human primate model appears more convincingly similar to the human condition and better suited to address therapeutic issues against tardive dyskinesia.
\end{abstract}

Keywords: tardive dyskinesia, stereotypies, vacuous chewing movements, antipsychotic drugs, dopamine receptors, non-human primates

\section{Introduction}

Tardive dyskinesia (TD) is a disabling and potentially irreversible motor complication encompassing all persistent, abnormal, involuntary hyperkinetic movements occurring in the setting of chronic therapy with dopamine receptor-blocking agents, such as antipsychotic drugs and metoclopramide [1]. The resulting movement disorder is most often stereotyped in nature and typically involves the orobuccolingual musculature. As TD remains an elusive drug complication over 50 years since its initial description, it is not surprising that the treatment options available are non-specific and produce mixed results.

Unfortunately, the early hope that second-generation (so-called atypical) antipsychotic drugs would afford a gradual disappearance of TD has been challenged by recent reports that one third of patients chronically exposed to antipsychotic drugs still develop TD [2-4]. The annual risk remains greater in older adults, particularly in those living with a dementing illness [5]. Severe

\footnotetext{
* Correspondence: pierre.j.blanchet@umontreal.ca

${ }^{1}$ Faculty of Dental Medicine, University of Montreal, PO Box 6128, Succ.

Centre-ville, Montreal, QC, H3C 3J7, Canada

Full list of author information is available at the end of the article
}

forms of TD also develop with the new antipsychotic drugs [6]. The persistence of TD in the community, and the enlarging spectrum of conditions for which antipsychotic drugs are prescribed (e.g., bipolar disorder, refractory depression), make it urgent to develop a better understanding of this hyperkinetic movement disorder, as well as novel preventive and palliative approaches. The use of animal models is inescapable and irreplaceable in reaching that goal. The advances made since the levodopa-induced dyskinesia primate model was introduced in neuroscience 25 years ago well illustrate that point $[7,8]$. Before mechanistic considerations are addressed, any experimental movement disorder model must first reproduce the phenomenology of the human condition, a test the levodopa-induced dyskinesia primate model has unequivocally passed. The purposeless hyperkinetic movements should be reproducible, quantifiable, and easily distinguishable from normal movements. This personal review of rodent as well as nonhuman primate TD models provides an opportunity to reflect upon the diversity of protocols, and lack of consensus thereof, and to suggest the most fruitful approaches. Cats and guinea pigs have rarely been used. We also take advantage of this exercise to compare the 
existing literature with our own recent experience with non-human primate modeling.

\section{Rat models}

The use of rats exposed to antipsychotic drugs for consecutive weeks has been proposed with variations since the early 70's. Originally, brief exposure of guinea pigs to chlorpromazine was followed by abrupt withdrawal and challenge with dopamine receptor agonists, which triggered stereotyped gnawing and sniffing [9]. The rapid onset of the motor stereotypies and need to sequentially use dopamine antagonist and agonist drugs certainly do not replicate the delayed course and spontaneous occurrence of TD in humans treated with dopamine receptor-blocking agents. Many laboratories have then characterized the spontaneous oral movements emerging during subchronic or chronic antipsychotic drug administration. The behavioural results obtained have been summarized in authoritative literature reviews $[10,11]$, which documented different patterns and descriptors of oral movements, most commonly reported as robust, seemingly purposeless, chewing activity (so-called vacuous chewing movements or $\mathrm{VCM}$ ), often fluctuating and occurring in short bursts, occasionally associated with bruxism and tongue protrusions. Rapid wide mouth openings and bursts of oromandibular tremor or twitching may be distinguished. In most reports, the proportion of animals displaying high VCM scores range from $30 \%$ to $50 \%$ according to the type of antipsychotic used, as well as the route of drug administration [11-18].

The VCMs and tongue protrusions are typically counted during repeated 2- to 5-min session blocks in an observation cage equipped with a mirror placed in the back to improve visibility, after a variable habituation period to the new environment (up to $1 \mathrm{~h}$ ), in single freely moving animals without access to food. Other investigators prefer to use stopwatches to record burst duration rather than single events. An observation tube, restraining the animal placed in front of a camera focused on the head, has been tested to optimize motor assessment, but requires much longer habituation to reduce stress effects [19]. This can be combined with a computer-assisted detection system to measure oral movements that cannot be visually quantified, but does not obviate the need for visual examination to distinguish purposeless chewing from bursts of jaw tremor or behavioural stereotypies temporally related to grooming or gnawing. Although drug-induced hypoactivity of the animal in the cage may facilitate and bias VCM detection, no significant change in locomotion was documented between VCM and VCM-free rats in one study, and grooming behaviour was not considered a hindrance to
VCM counting [20]. In contrast to human TD, extraoral dyskinesia has not been observed.

It is important but complex to distinguish early-onset from gradual late-onset VCMs in rodents during exposure to antipsychotic drugs. Early VCMs emerge rapidly (1-21 days), are sensitive to anticholinergic drugs, and may more closely reflect acute extrapyramidal symptoms (EPS) (parkinsonian tremor, dystonia), whereas more delayed VCMs (> 3 months) are insensitive to anticholinergics, and may better reflect tardive dyskinesia $[10,12,21]$. These two patterns are also associated with differences in neuropeptide gene expression in the striatum [21]. Thus, although similar from a behavioural perspective, early- and late-onset VCMs appear to have different pharmacological and neurochemical profiles. Unfortunately, the transitional time point between earlyand late-onset VCMs remains elusive. It is suggested that rats with late-onset high-VCM drug responses should be included in TD studies. In contrast to brief drug exposure protocols, long-term exposure seems more likely to promote the persistence of the VCM response following drug withdrawal, typically vanishing over a 2-week follow-up period [22], although longer persistence for several months has been documented $[10,23]$.

In contrast to levodopa-induced dyskinesia, continuous administration using depot formulations (e.g., haloperidol decanoate i.m.) produces a stronger VCM response compared to daily, dose-equivalent (i.p.), intermittent drug administration [11]. The importance of this observation is exemplified by the fact that continuous, but not intermittent, antipsychotic drug administration, delivered through a subcutaneous osmotic minipump, has generated high VCM scores, in spite of similar total daily doses [24,25]. Continuous levels of dopamine $D_{2}$ receptor occupancy during antipsychotic drug exposure increase the risk of receptor upregulation $[26,27]$, and could trigger distinct drug-induced neuroadaptation. Indeed, continuous, but not intermittent, haloperidol administration exacerbates psychostimulant drug reward behaviours and is associated with an aberrant psychostimulant-induced striatal gene regulation [28].

Since long-term drug exposure is not cost- and timeefficient, several laboratories still use a 3-week drug protocol to generate a VCM response, while others have attempted to find ways to accelerate and magnify rat TD-like oral activity with less variability. Old rats have been tested. Indeed, advancing age is the single most significant risk factor for early TD induction and persistence [29-31]. Old rats generally show a reduced level of spontaneous motor activity, but a higher level of oral movements in the unmedicated state, compared to 
young rats. During antipsychotic drug exposure, they may show a stable (ceiling effect) or heightened VCM response. It is unclear whether the use of aged rats provides a distinct advantage in experimental TD protocols $[14,32,33]$. Of practical importance in study design, certain strains such as the Long-Evans rats display a more robust VCM response in all treated individuals, whereas $38 \%$ of Sprague-Dawley rats never express VCM over 24 weeks [34]. Unlike in the human literature, the impact of gender and diabetes on experimental TD has been little addressed. One study reported a heightened VCM response in female mice that was inconsistent at different time points [35]. The influence of glucose metabolism on the VCM induction process and severity has not been investigated, but a surprising apparent reduction in apomorphine-enhanced VCM has been observed in diabetic rats exposed to haloperidol compared to control rats [36]. A few attempts to enhance the susceptibility to TD in rats with pre-existing central nervous system injury have been published $[37,38]$. While unnatural and remote from the experience of most people developing TD, these experiments may still provide clues about TD induction. Frontal cortex lesions generated more severe and persistent abnormal oral behaviours in adult rats after antipsychotic drug withdrawal [37], and neonatal dopamine denervation with 6-hydroxydopamine had an even greater impact on the severity of the VCM response triggered by haloperidol, which persisted for 8 months following drug withdrawal [38]. Partial dopamine loss may thus constitute a sensitization stage prior to the precipitation stage resulting from drug exposure, but whether this has some bearing on the vulnerability to TD seen in normal aging is undetermined. The sensitization stage may trigger additional pathogenic mechanisms contributing to the drug-induced neural changes conducive to TD, such as the sensitivity of dopamine $\mathrm{D}_{1}$ and serotonin $5-\mathrm{HT}_{2 \mathrm{C}}$ receptors [38], and/or lessening the endogenous adaptive response mounted to fend off TD.

One finding raising concern about the relevance of the VCM response is the apparent similar behaviour produced by the acute (3 days) or chronic (4-6 weeks) administration of the presynaptic monoamine depleter reserpine. This drug can trigger VCM, tongue protrusions, and facial twitching, which persist for periods extending up to 2 months following drug withdrawal [39]. These oral movements were more persistent in old than in young animals following drug withdrawal [32]. No general consensus exists concerning the validity of the reserpine model.

Thus, chronic antipsychotic drug exposure (typically with haloperidol) for at least 3-4 months appears to represent a standard approach to model TD in rats. The VCM response certainly does not display the complexity of human TD, and may appear very early in some animals during drug exposure. The model still provides insights about the human disorder, and has been proposed in experiments using antisense oligonucleotides to knockdown site-directed single target proteins that may be closely associated with the VCM response. For instance, intrastriatal infusion of oligonucleotide antisense to dopamine $\mathrm{D}_{1 \mathrm{~A}}$ receptor mRNA has selectively reduced receptor binding and VCMs in rats exposed to fluphenazine decanoate [40].

It is well established that haloperidol and other typical antipsychotic drugs $\left(D_{2}\right.$ receptor antagonists) upregulate dopamine $D_{2}$ receptors. This led to the suggestion that late-onset dyskinesia was a reflection of dopamine receptor supersensitivity [9]. However, several observations indicate that $D_{2}$ receptor upregulation alone is not sufficient to account for TD. In rats, haloperidolinduced $\mathrm{D}_{2}$ receptor upregulation develops early during treatment (within 15 days), while tardive VCMs only develop after much prolonged treatment [41,42]. Furthermore, $\mathrm{D}_{2}$ receptor upregulation similarly occurs in haloperidol-treated rats showing no or low VCMs and those displaying high VCM scores [11]. Similarly, no difference in striatal $\mathrm{D}_{2}$ receptor binding has been observed in patients with TD compared to antipsychotic drug-treated patients without TD [43].

Morphological changes observed in rats exposed to antipsychotics with high VCM scores included alterations in striatal synaptic morphology $[15,18]$, medial substantia nigra pars compacta nerve cell loss and atrophy particularly in aged rats [14], and alterations in nucleus accumbens dendritic spine density [16], but decreased spine density was not associated with VCM in the striatum [17]. Reductions in striatal choline acetyltransferase activity $[44,45]$ and in the number of large striatal (presumably cholinergic) interneurons $[45,46]$ have been reported following chronic antipsychotic drug exposure in rats, but the relevance of the results to TD and distinction from age-related effects remain unclear. Neurochemical data seem to point out to an important role of striatal dynorphin expression and/or increased glutamatergic activity $[13,15,16,18,21]$. However, the latter observations are correlative in nature, and no study designed to evaluate a causal link between these changes and induction of high VCM scores has been conducted so far.

\section{Transgenic mouse models}

Transgenic mice consist of strains whose genetic material has been deliberately modified using foreign DNA transfer into the host embryo by recombinant DNA technology. They are used to study the contribution of knockout genes on the response to antipsychotic drugs and on motor complications in particular. In the past, 
$\mathrm{D}_{3}$ receptor knockout mice have been tested to look at striatal gene and protein expression following the administration of different antipsychotic drugs $[47,48]$. We have examined Nur77 knockout mice and characterized their VCM response following the administration of haloperidol for up to 17 weeks [49]. Nur77 (NGFI-B, NR4A1) is a transcription factor of the nuclear receptor family expressed in dopaminoceptive circuits, whose striatal expression is upregulated by haloperidol in striatopallidal neurons [50,51]. Interestingly, Nur77 knockout mice display spontaneous VCMs in the unmedicated state and a stronger VCM response following haloperidol exposure compared to wild type mice (see accompanied Additional file 1: Table S1) [49]. This suggests that neurochemical changes induced by genetic deletion of Nur77 might have recapitulated some susceptibility processes observed in humans with TD. We also showed that a single nucleotide polymorphism (SNP, rs2603751) located in the 3'-UTR (untranslated regulatory region) of the Nur77 mRNA displayed a nominal association with the risk of developing TD, as well as with TD intensity based on Abnormal Involuntary Movement Scale (AIMS) scores in a group of schizophrenia patients [52]. More studies are underway to shed light on the signalling partners and cellular effects of this nuclear receptor in the basal ganglia, in normal and drugprimed conditions.

\section{Non-human primate model}

The initial attempts to model TD in macaques were not encouraging, with impermanent dyskinetic signs often admixed with acute dystonic reactions [54,55]. For these reasons, this TD model has been underused compared to the levodopa-induced dyskinesia primate model, explaining in part the existing gap in knowledge between the two iatrogenic disorders. With careful antipsychotic drug exposure, the abnormal movements observed are similar to those found in humans and typically stereotyped in nature, without concomitant acute dystonic reaction or interference with food intake and well-being (see accompanied Additional file 1: Table S1). Variable orofacial dyskinetic movements are seen (6 of 7 TD capuchins in our laboratory), including forehead contractions, chewing movements, tongue protrusions, and lip retraction (Figure 1). Neck rotation, brief back extension, and flexion/extension movements of the toes, are also seen. Upper limb chorea was occasionally observed. In some reports, the abnormal movements have persisted for several months following drug withdrawal.

Although the review of 21 published studies suggests marked interspecies differences in susceptibility that should be interpreted with caution in view of the various drug protocols used (see Additional file 2), the TD rate in primates is favourable and exceeds the annual incidence of $3-5 \%$ generally reported in human adults [74]. A cumulative account of the original experiments that have used Macaca species indicates that only $8 \%$ $(10 / 122)$ of the subjects chronically exposed to antipsychotic drugs alone developed TD. The mean ( \pm SD) drug exposure of $14.1( \pm 14.8)$ months was somewhat shorter than in capuchins. Baboons do not tolerate haloperidol well, and it is unknown whether they may safely be exposed to other first-generation antipsychotic drugs. Nonetheless, the dehydrated derivative of haloperidol, 4(4-chlorophenyl)-1-[4-(4-fluorophenyl)-4-oxobutyl]1,2,3,6-tetrahydropyridine (HPTP), was chronically administered with success to these animals and rapidly triggered TD [64]. In three New World monkey species, squirrels (Saimiri sciureus), capuchins (Cebus apella) and marmosets (Callithrix jacchus), TD developed in proportions of $0 \%(0 / 5$ animals in a single study), $45 \%$ (32/71, including $7 / 18$ observed in our laboratory) and $71 \%$ (12/17 in two studies), respectively. The onset of TD is unpredictable and highly variable in capuchins as well as in marmosets, with a mean latency of onset of $33.4( \pm 22.9)$ months and $18.0( \pm 8.5)$ months, respectively. In our 7 TD capuchins, the mean latency of onset was 17 months (median, 10 months; range 3-35 months). Interestingly, capuchins carry the gly 9 polymorphism in the dopamine $D_{3}$ receptor gene [75] that has been associated with TD in humans [76]. This genetic trait has not been sought in marmosets. The differential susceptibility of various non-human primate species to TD is reminiscent of the variable prevalence in TD reported in humans of diverse ethnic background, a very complex issue lacking conclusive evidence at present [77].

In the drug protocols examined (Additional file 2), haloperidol and fluphenazine were most often used and the duration of exposure generally extended to at least one year. Chronic oral drug administration was slightly more effective at triggering TD in capuchins than depot i.m. preparations, with incidence of $53 \%$ and $42 \%$, respectively, but the cumulative drug exposure resulting from these two drug regimens may well have differed. On the other hand, in common marmosets exposed to haloperidol [72,73], a depot i.m. preparation more effectively triggered TD than oral administration, a result which could be in line with the rat data discussed previously. Although the interrupted or sustained nature of the drug protocols pursued did not appear to correlate with TD susceptibility, temporary drug suspension did trigger persistent withdrawal-emergent TD in some animals [78,61], including 3 of our 18 capuchin monkeys. Thus, it appears reasonable to suspend drug exposure from time to time, at least to ensure that TD is not masked by parkinsonian features. 


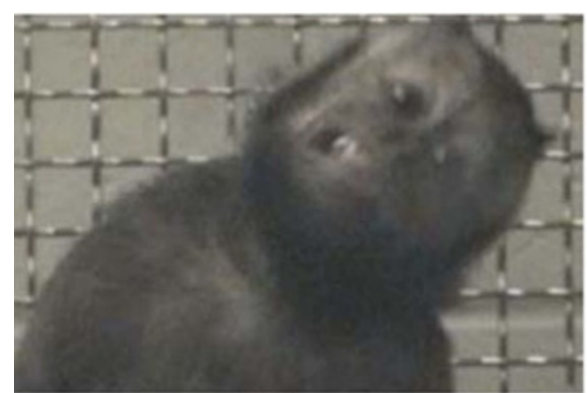

Cb1

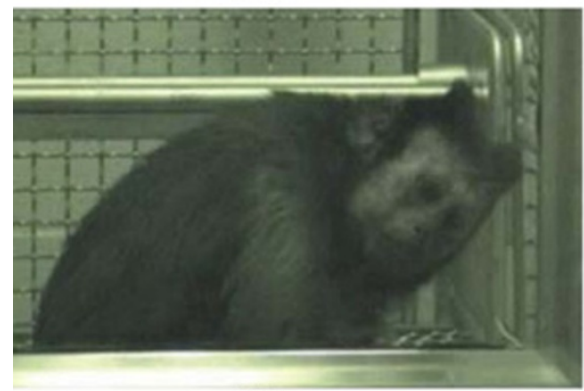

Cb4

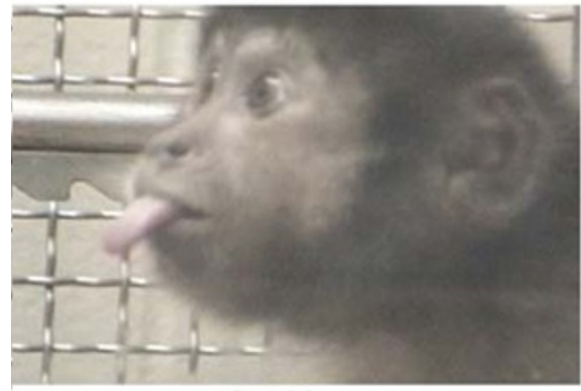

Cb529

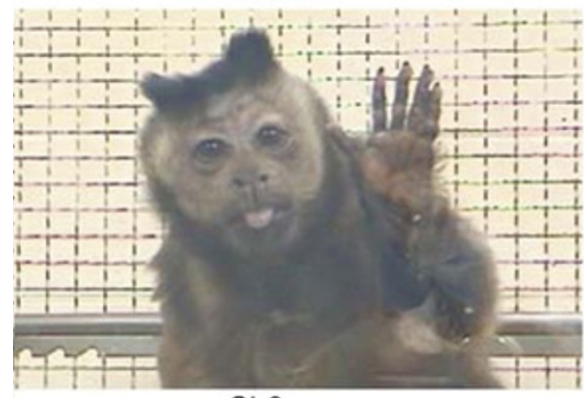

Cb3

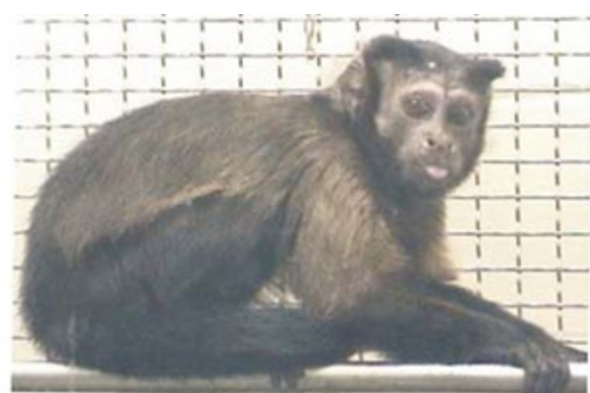

Cb16

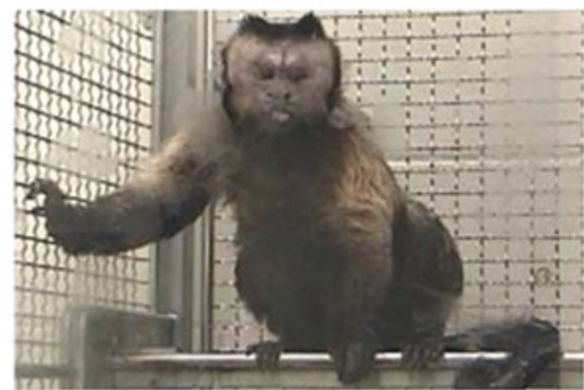

$\mathrm{Cb} 8$

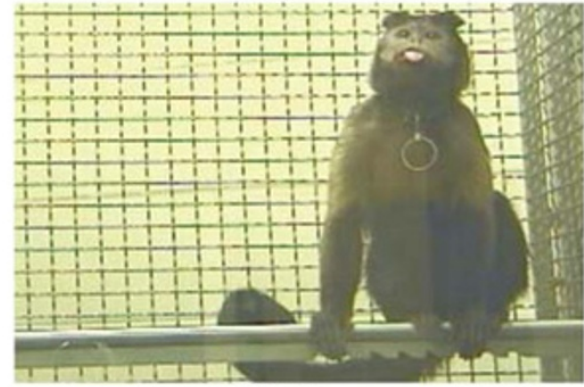

Cb18

Figure 1 Seven capuchins displaying tardive dyskinetic movements causing variable tongue protrusions, as well as forehead contractions, lip retraction, and neck twisting.

The recognition and rating of TD are easy in nonhuman primates $[62,72]$. We have used a primate equivalent of the Abnormal Involuntary Movements Scale (AIMS) to blindly score body segments (orofacial [forehead, lips, tongue, jaw], neck, trunk, and each limb) between 0-4 points (absent to severe intensity), for a maximum score of 40 points. The intensity of TD in our animals was generally mild, and orofacial scores accounted for approximately $40 \%$ of the total TD score.
As reported previously [61], stress enhances TD and should be kept constant as much as possible. Reminiscent of the diurnal variability in orofacial TD measured in a fraction of TD patients [79], TD intensity showed some variability in the short term (Figure 2), and the spontaneous dispersion of TD ratings $(\mathrm{N}=6)$ in 3 data sets of normal distribution generated 4 weeks apart revealed a mean coefficient of variation of $31.5 \%$ (range 10.2-49.5). We calculated that a sample size of 7 


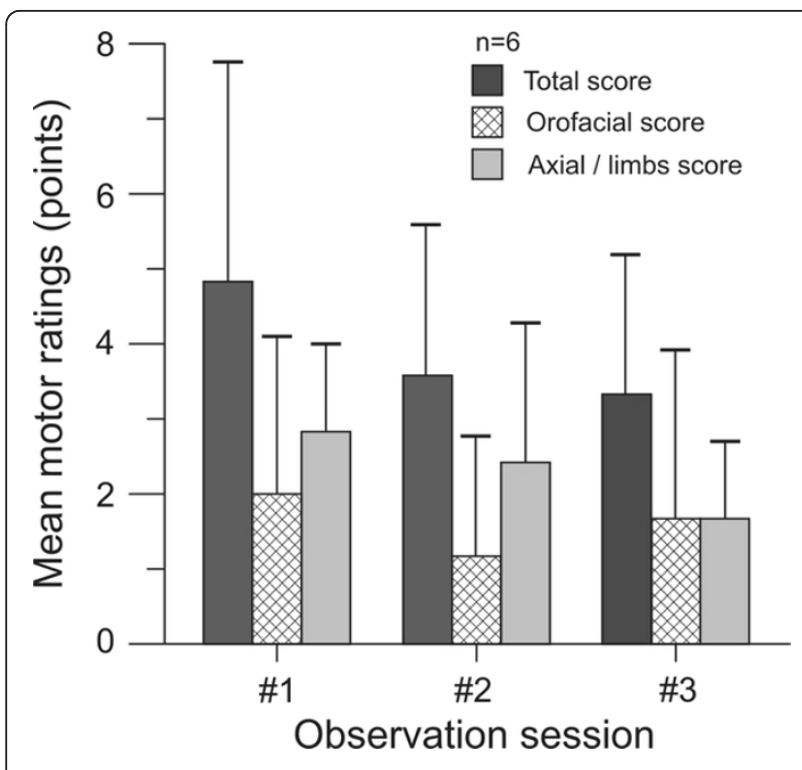

Figure 2 Mean $( \pm S D)$ tardive dyskinesia scores obtained in 6 animals rated on 3 different occasions 4 weeks apart. Individual scores represent the sum of several body parts. The mean coefficient of variation calculated from this data set with normal distribution is $31.5 \%$.

monkeys would be necessary to demonstrate the antidyskinetic properties of an investigational drug, taking into account the spontaneous variability in TD scores, and a power of $80 \%$ and alpha value of 0.05 to detect an antidyskinetic effect size of at least $50 \%$ relative to baseline scores.

Although the TD incidence in capuchin monkeys exceeds several-fold that in humans and macaques, the unpredictability, long delay of induction, and cost of this experimental TD model, constitute impediments to broad applications. As in the rodent model, certain factors have been proposed to accelerate experimental TD induction. High drug dosing may seem desirable to sensitize basal ganglia circuits and promote TD induction (Additional file 2), but this often triggers acute dystonic reactions even during maintenance of drug exposure [80]. Thus, we have elected to administer low i.m. weekly doses. Such dosing frequency could better account for the faster metabolism and clearance of haloperidol reported in non-human primates compared to humans [81]. It is unknown whether antipsychotic drug disposal in rhesus is faster than in capuchins, but this could in part explain their apparent low TD susceptibility. As in rats, acute drug challenge with a dopamine agonist has been proposed in monkeys as a way to reflect the behavioural sensitivity of animals chronically exposed to antipsychotic drugs and enhance experimental TD, but the impact of this strategy wanes over time and its validity as a model has been questioned [82]. The age of the animals has been little examined [61].
Since the availability of monkeys over 24 years of age is limited, this strategy is not widely applicable. Bilateral ovariectomy was first performed in our females to reduce gonadal hormone modulation on brain dopamine and GABA receptors during the estrous cycle [83-86], as proposed in the levodopa-induced dyskinesia primate model [87]. Although it is intuitively beneficial to reproduce the postmenopausal hormonal status of women most at risk for TD [88], this procedure does not make a senescent brain and its place as a TD-enhancing strategy remains undetermined. The use of common marmosets has also been suggested since they tend to display TD sooner (see Additional file 2), often within the first year after antipsychotic drug initiation. This carries definite advantages in lowering cohort size and cost, but the exceptionally high cumulative TD incidence in that species, reaching $100 \%$ in one report [72], raises some concerns about the immediate applicability of the marmoset model to human TD. Other strategies could eventually be developed to increase TD susceptibility in monkeys, with the aim to dampen neuroadaptive mechanisms [49], or inversely, to amplify abnormal molecular signalling triggered by antipsychotic drugs [89-92].

Neuropathological examination of baboons with TD following exposure to the dehydrated product of haloperidol revealed no obvious changes in neuronal density and neuropeptide content (substance P, enkephalin) in the basal ganglia relative to control animals, but gliosis in the caudate nucleus was observed in the TD group [64]. A $25 \%$ reduction in density of the magnocellular cholinergic neurons was found in the anterior portion of the nucleus basalis of Meynert in the TD brains only, while the striatal cholinergic interneurons were spared. The functional impact of this loss on the activity of the cortico-subcortical circuits, and on the subthalamic nucleus in particular, remains undetermined. The regional reductions in glutamate decarboxylase (GAD) activity found initially in the substantia nigra only in capuchins with severe TD left untreated for 2 months before sacrifice, affecting to a lesser extent the medial globus pallidus and subthalamic nucleus $[80,70]$, were not consistently replicated in subsequent studies [91]. A single 2-deoxyglucose study involving 4 capuchins with chronic TD left untreated for 4 months showed decreased uptake levels in the medial globus pallidus and ventral (VA/VL) thalamus compared to 3 controls, suggesting parallel changes in synaptic activity within the inputs to these structures susceptible to promote dyskinesia [92].

In conclusion, the animal models of TD discussed are complementary and offer different ways to examine various aspects of antipsychotic drug responses. The latency of onset, individual susceptibility, phenomenologic expression of the purposeless movements, and 
persistence of TD signs between drug dosing, make the non-human primate TD model convincingly similar to the human condition, and best suited to address therapeutic issues. In our view, this model will continue to contribute to our understanding of TD.

\section{Financial Disclosure of all authors (for the preceding 12 months)}

Pierre Blanchet and Daniel Lévesque have received research funding from the Canadian Institutes of Health Research (Ottawa) and the National Alliance for Research on Schizophrenia and Depression (NARSAD). P. Blanchet also received speaker fees from Biovail Pharmaceuticals Canada, Novartis Pharma Canada, and Teva Canada Innovation. Marie-Thérèse Parent and Pierre Rompré have no independent public or private source of financial support to declare.

\section{Additional material}

Additional file 1: Table S1. Experience of chronic antipsychotic drug exposure in non-human primates [53-56,58,62-65,80,83-92].

Additional file 2: Segment \#1 shows typical haloperidol-induced vacuous chewing movements in a wild type mouse. Occasional, brief vertical jaw movements are observed. The next segments show six different capuchin monkeys still exposed to a maintenance intramuscular weekly dose of antipsychotic drug when the videoclips were captured. The phenomenology of the purposeless movements includes variable orofacial, axial, and foot dyskinesias, at times admixed with mild dystonic features. The animals are otherwise in good condition and able to feed, groom, ambulate, and interact with peers.

\section{Acknowledgements}

The Authors wish to thank the staff members of the animal care and use facility at the University of Montreal main campus for their constant support. Supported by grants from the Canadian Institutes of Health Research.

\section{Author details}

${ }^{1}$ Faculty of Dental Medicine, University of Montreal, PO Box 6128, Succ. Centre-ville, Montreal, QC, H3C 3J7, Canada. ${ }^{2}$ Central Nervous System Research Group, University of Montreal, PO Box 6128, Succ. Centre-ville, Montreal, QC, H3C 3J7, Canada. ${ }^{3}$ University of Montreal Hospital Centre (C.H. U. Montreal), 1560 Sherbrooke St. East, Montreal, QC, H2L 4M1, Canada. ${ }^{4}$ Louis-H. Lafontaine Hospital, 7401 Hochelaga St., Montreal, QC H1N 3M5, Canada. ${ }^{5}$ Faculty of Pharmacy, University of Montreal, PO Box 6128, Succ. Centre-ville, Montreal, QC, H3C 3J7, Canada.

\section{Authors' contributions}

All authors read and approved the final manuscript.

\section{Competing interests}

The authors declare that they have no competing interests.

Received: 18 November 2011 Accepted: 9 March 2012

Published: 9 March 2012

\section{References}

1. Blanchet PJ: Antipsychotic drug-induced movement disorders. Can J Neurol Sci 2003, 30(Suppl 1):S101-107.
2. Halliday J, Farrington S, Macdonald S, MacEwan T, Sharkey V, McCreadie R: Nithsdale Schizophrenia Surveys 23: movement disorders. 20-year review. Br J Psychiatry 2002, 181:422-427.

3. Marshall DL, Hazlet TK, Gardner JS, Blough DK: Neuroleptic drug exposure and incidence of tardive dyskinesia: a records-based case-control study. J Man Care Pharm 2002, 8:259-265.

4. Woods SW, Morgenstern H, Saksa JR, Walsh BC, Sullivan MC, Money R, Hawkins KA, Gueorguieva RV, Glazer WM: Incidence of tardive dyskinesia with atypical versus conventional antipsychotic medications: a prospective cohort study. J Clin Psychiatry 2010, 71:463-474.

5. Lee PE, Sykora K, Gill SS, Mamdani M, Marras C, Anderson G, Shulman KI, Stukel T, Normand SL, Rochon PA: Antipsychotic medications and druginduced movement disorders other than parkinsonism: a populationbased cohort study in older adults. J Am Geriatr Soc 2005, 53:1374-1379.

6. de Leon J: The effect of atypical versus typical antipsychotics on tardive dyskinesia: a naturalistic study. Eur Arch Psychiatry Clin Neurosci 2007 257:169-172.

7. Blanchet PJ, Calon F, Morissette M, Hadj Tahar A, Bélanger N, Samadi P, Grondin R, Grégoire L, Meltzer L, Di Paolo T, Bédard PJ: Relevance of the MPTP primate model in the study of dyskinesia priming mechanisms. Parkinsonism Rel Disord 2004, 10:297-304.

8. Jenner P: From the MPTP-treated primate to the treatment of motor complications in Parkinson's disease. Parkinsonism Rel Disord 2009, , 15S: S18-S23.

9. Klawans $\mathrm{HL}$ Jr, Rubovits R: An experimental model of tardive dyskinesia. $J$ Neural Transm 1972, 33:235-246.

10. Waddington JL: Spontaneous orofacial movements induced in rodents by very long-term neuroleptic drug administration: phenomenology, pathophysiology and putative relationship to tardive dyskinesia. Psychopharmacol (Berl) 1990, 101:431-447.

11. Turrone $P$, Remington $G$, Nobrega JN: The vacuous chewing movement (VCM) model of tardive dyskinesia revisited: is there a relationship to dopamine $D_{2}$ receptor occupancy? Neurosci Biobehav Rev 2002, 26:361-380.

12. Marchese G, Bartholini F, Casu MA, Ruiu S, Casti P, Congeddu E, Tambaro S, Pani L: Haloperidol versus risperidone on rat "early onset" vacuous chewing. Behav Brain Res 2004, 149:9-16.

13. Andreassen OA, Meshul CK, Moore C, Jorgensen HA: Oral dyskinesias and morphological changes in rat striatum during long-term haloperidol administration. Psychopharmacol (Berl) 2001, 157:11-19.

14. Andreassen OA, Ferrante RJ, Aamo TO, Beal MF, Jorgensen HA: Oral dyskinesias and histopathological alterations in substantia nigra after long-term haloperidol treatment of old rats. Neuroscience 2003, 122:717-725.

15. Meshul CK, Andreassen $O A$, Allen $C$, Jorgensen HA: Correlation of vacuous chewing movements with morphological changes in rats following 1year treatment with haloperidol. Psychopharmacol (Berl) 1996, 125:238-247.

16. Meredith GE, De Souza IE, Hyde TM, Tipper G, Wong ML, Egan MF: Persistent alterations in dendrites, spines, and dynorphinergic synapses in the nucleus accumbens shell of rats with neuroleptic-induced dyskinesias. J Neurosci 2000, 20:7798-7806.

17. Kelley JJ, Gao XM, Tamminga CA, Roberts RC: The effect of chronic haloperidol treatment on dendritic spines in the rat striatum. Exp Neurol 1997, 146:471-478

18. Roberts RC, Lapidus B: Ultrastructural correlates of haloperidol-induced oral dyskinesias in rats: a study of unlabeled and enkephalin-labeled striatal terminals. J Neural Transm 2003, 110:961-975.

19. Ellison G, See RE: Rats administered chronic neuroleptics develop oral movements which are similar in form to those in humans with tardive dyskinesia. Psychopharmacol (Berl) 1989, 98:564-566.

20. De Souza IEJ, Dawson NM, Clifford JJ, Waddington JL, Meredith GE: Relationship of orofacial movements to behavioural repertoire as assessed topographically over the course of 6-month haloperidol treatment followed by 4-month withdrawal. Psychopharmacol 2003, 169:28-34.

21. Egan MF, Hurd Y, Ferguson J, Bachus SE, Hamid EH, Hyde TM: Pharmacological and neurochemical differences between acute and tardive vacuous chewing movements induced by haloperidol. Psychopharmacol (Berl) 1996, 127:337-345. 
22. Clow A, Theodorou A, Jenner P, Marsden CD: Cerebral dopamine function in rats following withdrawal from one year of continuous neuroleptic administration. Eur J Pharmacol 1980, 63:145-157.

23. Waddington JL, Cross AJ, Gamble SJ, Bourne RC: Spontaneous orofacial dyskinesia and dopaminergic function in rats after 6 months of neuroleptic treatment. Science 1983, 220:530-532.

24. Turrone P, Remington G, Kapur S, Nobrega JN: Differential effects of within-day continuous vs transient dopamine $D_{2}$ receptor occupancy in the development of vacuous chewing movements (VCMs) in rats. Neuropsychopharmacol 2003, 28:1433-1439.

25. Turrone $P$, Remington $G$, Kapur S, Nobrega JN: Continuous but not intermittent olanzapine infusion induces vacuous chewing movements in rats. Biol Psychiatry 2005, 57:406-411.

26. Samaha AN, Reckless GE, Seeman P, Diwan M, Nobrega JN, Kapur S: Less is more: antipsychotic drug effects are greater with transient rather than continuous delivery. Biol Psychiatry 2008, 64:145-152

27. Ginovart N, Wilson AA, Hussey D, Houle S, Kapur S: D2-receptor upregulation is dependent upon temporal course of D2-occupancy: a longitudinal [ ${ }^{11} \mathrm{C}$-raclopride PET study in cats. Neuropsychopharmacol 2009, 34:662-671.

28. Bédard AM, Maheux J, Lévesque D, Samaha AN: Continuous, but not intermittent, antipsychotic drug delivery intensifies the pursuit of reward cues. Neuropsychopharmacol 2011, 36:1248-1259.

29. Harris MJ, Panton D, Caligiuri MP, Krull AJ, Tran-Johnson TK, Jeste DV: High incidence of tardive dyskinesia in older outpatients on low doses of neuroleptics. Psychopharmacol Bull 1992, 28:87-92.

30. Cavallaro R, Regazzetti MG, Mundo E, Brancato V, Smeraldi E: Tardive dyskinesia outcomes: clinical and pharmacologic correlates of remission and persistence. Neuropsychopharmacol 1993, 8:233-239.

31. Jeste DV, Caligiuri MP, Paulsen JS, Heaton RK, Lacro JP, Harris MJ, Bailey A, Fell RL, McAdams LA: Risk of tardive dyskinesia in older patients. A prospective longitudinal study of 266 outpatients. Arch Gen Psychiatry 1995, 52:756-765.

32. Bergamo M, Abilio VC, Queiroz CM, Barbosa-Junior HN, Abdanur LR, FrussaFilho R: Effects of age on a new animal model of tardive dyskinesia. Neurobiol Aging 1997, 18:623-629.

33. Steinpreis RE, Parret F, Summ RM, Panos JJ: Effects of clozapine and haloperidol on baseline levels of vacuous jaw movements in aged rats. Behav Brain Res 1997, 86:165-169.

34. Tamminga CA, Dale JM, Goodman L, Kaneda H, Kaneda N: Neurolepticinduced vacuous chewing movements as an animal model of tardive dyskinesia: a study in three rat strains. Psychopharmacol (Berl) 1990, 102:474-478.

35. Silva RH, Abílio VC, Torres-Leite D, Bergamo M, Chinen CC, Claro FT, de Cássia Carvalho R, Frussa-Filho R: Concomitant development of oral dyskinesia and memory deficits in reserpine-treated male and female mice. Behav Brain Res 2002, 132:171-177.

36. Sumiyoshi T, Ichikawa J, Meltzer HY: Increased S(-)-apomorphine-induced vacuous chewing and attenuated effect of chronic haloperidol treatment in streptozotocin-induced diabetic rat. Pharmacol Biochem Behav 1997, 57:19-22.

37. Glassman RB, Glassman HN: Oral dyskinesia in brain-damaged rats withdrawn from a neuroleptic: implications for models of tardive dyskinesia. Psychopharmacol (Berl) 1980, 69:19-25.

38. Kostrzewa RM, Huang N-Y, Kostrzewa JP, Nowak P, Brus R: Modeling tardive dyskinesia: predictive $5-\mathrm{HT}_{2}$ receptor antagonist treatment. Neurotox Res 2007, 11:41-50.

39. Neisewander JL, Castañeda E, Davis DA: Dose-dependent differences in the development of reserpine-induced oral dyskinesias in rats: support for a model of tardive dyskinesia. Psychopharmacol (Berl) 1994, 116:79-84

40. Van Kampen JM, Stoessl AJ: Dopamine $D_{1 A}$ receptor function in a rodent model of tardive dyskinesia. Neuroscience 2000, 101:629-635.

41. Fibiger HC, Lloyd KG: Neurobiological substrates of tardive dyskinesia: the GABA hypothesis. Trends Neurosci 1984, 7:462-464.

42. Waddington $\mathrm{J}$ : Further anomalies in the dopamine receptor supersensitivity hypothesis of tardive dyskinesia. Trends Neurosci 1985 8:200.

43. Andersson U, Eckernas SA, Hartvig P, Ulin J, Langstrom B, Häggström JE: Striatal binding of 11 C-NMSP studied with positron emission tomography in patients with persistent tardive dyskinesia: no evidence for altered dopamine D2 receptor binding. J Neural Transm Gen Sect 1990, 79:215-226.

44. Pedata F, Sorbi S, Pepeu G: Choline high-affinity uptake and metabolism and choline acetyltransferase activity in the striatum of rats chronically treated with neuroleptics. J Neurochem 1980, 35:606-611.

45. Mahadik SP, Laev H, Korenovsky A, Karpiak SE: Haloperidol alters rat CNS cholinergic system: enzymatic and morphological analyses. Biol Psychiatry 1988, 24:199-217.

46. Jeste DV, Lohr JB, Manley M: Study of neuropathologic changes in the striatum following 4, 8 and 12 months of treatment with fluphenazine in rats. Psychopharmacol 1992, 106:154-160.

47. Carta AR, Gerfen CR: Lack of a role for the D3 receptor in clozapine induction of c-fos demonstrated in D3 dopamine receptor-deficient mice. Neuroscience 1999, 90:1021-1029.

48. Robertson GS, Lee CJ, Sridhar K, Nakabeppu Y, Cheng M, Wang YM, Caron MG: Clozapine-, but not haloperidol-, induced increases in $\triangle$ FosBlike immunoreactivity are completely blocked in the striatum of mice lacking D3 dopamine receptors. Eur J Neurosci 2004, 20:3189-3194.

49. Ethier I, Kagechika H, Shudo K, Rouillard C, Lévesque D: Docosahexaenoic acid reduces haloperidol-induced dyskinesias in mice: involvement of Nur77 and retinoid receptors. Biol Psychiatry 2004, 56:522-526.

50. Beaudry G, Langlois M-C, Weppe I, Rouillard C, Lévesque D: Contrasting patterns and cellular specificity of transcriptional regulation of the nuclear receptor nerve growth factor-inducible B by haloperidol and clozapine in the rat forebrain. J Neurochem 2000, 75:1694-1702.

51. Langlois M-C, Beaudry G, Zekki H, Rouillard C, Lévesque D: Impact of antipsychotic drug administration on the expression of nuclear receptors in the neocortex and striatum of the rat brain. Neuroscience 2001, 106:117-128.

52. Novak G, Gallo A, Zai CC, Meltzer HY, Lieberman JA, Potkin SG, Voineskos AN, Remington G, Kennedy JL, Levesque D, Le Foll B: Association of the orphan nuclear receptor NR4A1 with tardive dyskinesia. Psychiatr Genet 2010, 20:39-43

53. Paulson GW: Dyskinesias in monkeys. In In Advances in Neurology. Volume 1. Edited by: Barbeau A, Chase TN, Paulson GW. New York: Raven; 1973:647-650.

54. Gunne L-M, Bárány S: Haloperidol-induced tardive dyskinesias in monkeys. Psychopharmacol (Berl) 1976, 50:237-240.

55. Gunne L-M, Bárány S: A monitoring test for the liability of neuroleptic drugs to induce tardive dyskinesia. Psychopharmacol (Berl) 1979 63:195-198.

56. Bédard P, De Lean J, Lafleur J, Larochelle L: Haloperidol-induced dyskinesias in the monkey. Can J Neurol Sci 1977, 4:197-201.

57. Casey D: Neuroleptic-induced acute extrapyramidal syndromes and tardive dyskinesia. Psychiatr Clin N Amer 1993, 16:689-710.

58. Halliday GM, Pond SM, Cartwright H, McRitchie DA, Castagnoli N Jr, Van der Schyf $\mathrm{CJ}$ : Clinical and neuropathological abnormalities in baboons treated with HPTP, the tetrahydropyridine analog of haloperidol. Exp Neurol 1999, 158:155-163.

59. Werge T, Elbaek Z, Andersen MB, Lundbaek JA, Rasmussen HB: Cebus apell, a nonhuman primate highly susceptible to neuroleptic side effects, carries the GLY9 dopamine receptor D3 associated with tardive dyskinesia in humans. The Pharmacogenomics J 2003, 3:97-100.

60. Steen VM, Lovlie R, MacEwan T, McCreadie RG: Dopamine D3-receptor gene variant and susceptibility to tardive dyskinesia in schizophrenic patients. Mol Psychiatry 1997, 2:139-145

61. Swartz JR, Burgoyne K, Smith M, Gadasally R, Ananth J, Ananth K: Tardive dyskinesia and ethnicity: review of the literature. Ann Clin Psychiatry 1997, 9:53-59.

62. Klintenberg R, Gunne L, Andrén PE: Tardive dyskinesia model in the common marmoset. Mov Disord 2002, 17:360-365.

63. Jackson MJ, Al-Barghouthy G, Pearce RKB, Smith L, Hagan JJ, Jenner P: Effect of $5-\mathrm{HT}_{1 \mathrm{~B} / \mathrm{D}}$ receptor agonist and antagonist administration on motor function in haloperidol and MPTP-treated common marmosets. Pharmacol Biochem Behav 2004, 79:391-400.

64. Lifshitz K, O'Keeffe RT, Lee KL, Linn GS, Mase D, Avery J, Lo ES, Cooper TB: Effect of extended depot fluphenazine treatment and withdrawal on social and other behaviors of Cebus apell monkeys. Psychopharmacol (Berl) 1991, 105:492-500.

65. Domino EF: Induction of tardive dyskinesia in Cebus apella and Macaca speciosa monkeys: a review. In In Dyskinesia - Research and Treatment 
(Psychopharmacology Supplementum 2). Edited by: Casey DE, Chase TN, Christensen AV, Gerlach J. Berlin Heidelberg: Springer; 1985:217-223.

66. Baca-Garcia E, Stanilla JK, Büchel C, Gattaz WF, de Leon J: Diurnal variability of orofacial dyskinetic movements. Pharmacopsychiat 1999, 32:73-75.

67. Gunne LM, Häggström JE, Johansson P, Levin ED, Terenius L: Neurobiochemical changes in tardive dyskinesia. L'Encéphale 1988, XIV: 167-173.

68. Stafford JEH, Jackson LS, Forrest TJ, Barrow A, Palmer RF: Haloperidol pharmacokinetics: a preliminary study in rhesus monkeys using a new radioimmunoassay procedure. J Pharmacol Methods 1981, 6:261-279.

69. Casey DE: Behavioral effects of long-term neuroleptic treatment in Cebus monkeys. In In Dyskinesia - Research and Treatment (Psychopharmacology Supplementum 2). Edited by: Casey DE, Chase TN, Christensen AV, Gerlach J. Berlin Heidelberg: Springer; 1985:211-216.

70. Bédard PJ, Boucher R: Estradiol can suppress haloperidol-induced supersensitivity in dyskinetic monkeys. Neurosci Lett 1986, 64:206-210.

71. Van Hartesveldt C, Joyce JN: Effects of estrogen on the basal ganglia. Neurosci Biobehav Rev 1986, 10:1-14.

72. Fields JZ, Gordon JH: Permanent haloperidol-induced dopamine receptor up-regulation in the ovariectomized rat. Brain Res Bull 1991, 26:549-552.

73. Bossé $R$, Di Paolo T: The modulation of brain dopamine and GABA-A receptors by estradiol: a clue for CNS changes occurring at menopause. Cell Mol Neurobiol 1996, 16:199-212.

74. Calon F, Goulet M, Blanchet PJ, Martel JC, Piercey MF, Bédard PJ, Di Paolo T: Levodopa or D2 agonist induced dyskinesia in MPTP monkeys: correlation with changes in dopamine and GABA-A receptors in the striatopallidal complex. Brain Res 1995, 680:43-52.

75. Yassa R, Jeste DV: Gender differences in tardive dyskinesia: a critical review of the literature. Schizophr Bull 1992, 18:701-715.

76. Nguyen TV, Kosofsky BE, Birnbaum R, Cohen BM, Hyman SE: Differential expression of c-fos and zif268 in rat striatum after haloperidol, clozapine, and amphetamine. Proc Natl Acad Sci USA 1992, 89:4270-4274.

77. Simpson CS, Morris BJ: Haloperidol and fluphenazine induce junB gene expression in rat striatum and nucleus accumbens. J Neurochem 1994, 63:1955-1961.

78. Boegman RJ, Vincent SR: Involvement of adenosine and glutamate receptors in the induction of $\mathrm{c}$-fos in the striatum by haloperidol. Synapse 1996, 22:70-77.

79. Wirtshafter D, Asin KE: Effects of haloperidol and clozapine on Fos expression in the primate striatum. NeuroReport 2003, 14:2429-2432.

80. Gunne L-M, Häggström J-E, Sjöquist B: Association with persistent neuroleptic-induced dyskinesia of regional changes in brain GABA synthesis. Nature 1984, 309:347-349.

81. Gunne LM, Andrén PE: An animal model for coexisting tardive dyskinesia and tardive parkinsonism: a glutamate hypothesis for tardive dyskinesia. Clin Neuropharmacol 1993, 16:90-95.

82. Mitchell IJ, Crossman AR, Liminga U, Andren P, Gunne LM: Regional changes in 2-deoxyglucose uptake associated with neuroleptic-induced tardive dyskinesia in the Cebus monkey. Mov Disord 1992, 7:32-37.

83. Deneau G, Crane GE: Dyskinesia in rhesus monkeys tested with high doses of chlorpromazine. A multidisciplinary workshop: Psychotropic drugs and dysfunctions of the basal ganglia Washington: Public Health Service Publication No. 1938; 1969, 12-14.

84. McKinney WT, Moran EC, Kraemer GW, Prange AJ Jr: Long-term chlorpromazine in rhesus monkeys: production of dyskinesias and changes in social behavior. Psychopharmacol (Berl) 1980, 72:35-39.

85. Lidow MS, Goldman-Rakic PS: A common action of clozapine, haloperidol, and remoxipride on $D_{1}$ - and $D_{2}$-dopaminergic receptors in the primate cerebral cortex. Proc Natl Acad Sci USA 1994, 91:4353-4356.

86. Lidow MS, Elsworth JD, Goldman-Rakic PS: Down-regulation of the D1 and D5 dopamine receptors in the primate prefrontal cortex by chronic treatment with antipsychotic drugs. J Pharmacol Exp Ther 1997, 281:597-603.

87. O'Connor JA, Hasenkamp W, Horman BM, Muly EC, Hemby SE: Region specific regulation of NR1 in rhesus monkeys following chronic antipsychotic drug administration. Biol Psychiatry 2006, 60:659-662.

88. O'Connor JA, Muly EC, Arnold SE, Hemby SE: AMPA receptor subunit and splice variant expression in the DLPFC of schizophrenic subjects and rhesus monkeys chronically administered antipsychotic drugs. Schizophr Res 2007, 90:28-40.
89. Dorph-Petersen KA, Pierri JN, Perel JM, Sun Z, Sampson AR, Lewis DA: The influence of chronic exposure to antipsychotic medications on brain size before and after tissue fixation: a comparison of haloperidol and olanzapine in macaque monkeys. Neuropsychopharmacol 2005, 30:1649-1661.

90. Weiss B, Santelli S, Lusink G: Movement disorders induced in monkeys by chronic haloperidol treatment. Psychopharmacol (Berl) 1977, 53:289-293.

91. Bárány S, Ingvast A, Gunne L-M: Development of acute dystonia and tardive dyskinesia in Cebus monkeys. Res Commun Chem Pathol Pharmacol 1979, 25:269-279.

92. Kovacic B, Domino EF: A monkey model of tardive dyskinesia (TD): evidence that reversible TD may turn into irreversible TD. $J$ Clin Psychopharmacol 1982, 2:305-307.

doi:10.1186/1744-9081-8-12

Cite this article as: Blanchet et al: Relevance of animal models to

human tardive dyskinesia. Behavioral and Brain Functions 2012 8:12.

\section{Submit your next manuscript to BioMed Central and take full advantage of:}

- Convenient online submission

- Thorough peer review

- No space constraints or color figure charges

- Immediate publication on acceptance

- Inclusion in PubMed, CAS, Scopus and Google Scholar

- Research which is freely available for redistribution

Submit your manuscript at www.biomedcentral.com/submit
Biomed Central 